\title{
The Irula Co-operative Venom Centre, India
}

\author{
Romulus Whitaker and Harry V. Andrews
}

\begin{abstract}
When the Indian Government banned the export of snakeskins in 1976, the Irulas - a tribal people whose traditional skills included snake-catching - lost a major source of income. The authors describe how the Irula Co-operative Venom Centre was established to replace this lost income and at the same time exploit a valuable wildlife resource in a way that is apparently sustainable. More research is needed, however, to ensure that the project is viable in the long term.
\end{abstract}

\section{Introduction}

In 1976 the export of snake skins from India was banned because of the ecological role of snakes as rodent predators. The Irula tribal people of Tamil Nadu, numbering over 20,000, were the main suppliers of snake skins to the industry and many were left destitute following the ban. The Irulas are the aboriginal inhabitants of the plains and scrub forests of Chinglepet District near Madras. Most of them still subsist to a large extent on hunting and gathering, and their expertise in hunting deadly snakes is almost legendary locally.

In 1978 the first author assisted a group of Irulas, with whom he had been working for a decade, in forming a registered co-operative society. The initial primary objective of the cooperative was to establish a venom centre. This was considered to be the best system of managing a tribal business because, if run properly, a co-operative ensures equal income opportunities for all its members. The plan was that, under licence from Tamil Nadu Forest Department, Irulas would bring freshly caught venomous snakes to the centre for venom extraction. The venom would be dried and sold to Indian manufacturers of antivenom serum and the snakes released back to the wild after 3 weeks in captivity (Whitaker, 1979; Whitaker and Whitaker, 1987).

Now, after 15 years, the Irula Co-operative Venom Centre is a small but flourishing example of how a tribal community can maintain its traditional skills and lifestyle through the sustained yield use of wildlife. Starting as
President of the Society, the first author is now a technical adviser because the work is now handled and mostly managed by the tribal people themselves - from the skilled and dangerous job of capturing snakes and extracting their venom to the operation of the lyophilizer (freeze drier), which processes the venom. This is an important project for India at this time (when conservation is gearing up towards wildlife management) because it is the only one that uses wild animals.

\section{Use of snake venom as a resource}

World-wide, perhaps 30,000-40,000 people die annually from snake bites and 10,000 of these die in India (Swaroop and Grab, 1954; Sawai and Homma, 1976). The only effective cure for a serious snake bite is antivenom serum, made by immunizing horses with gradually increasing doses of raw venom. Thus, there is a continuous need for stocks of snake venoms of the medically important species. In India, the four snakes that cause the vast majority of fatal bites are the cobra Naja naja, krait Bungarus caeruleus, Russell's viper Vipera russellii and saw-scaled viper Echis carinatus - all are species found throughout much of the country.

Rearing snakes in captivity has proved to be expensive and difficult, particularly in the large numbers needed to collect enough venom to supply the demand for antivenom production. Therefore, wild snakes are exploited world-wide for their venoms. Most 


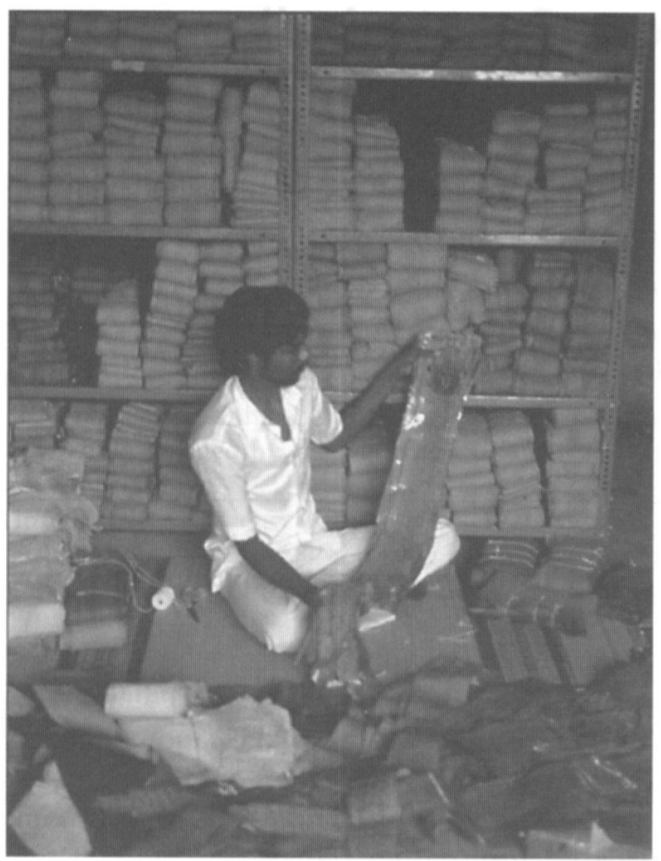

venom-production schemes involve local people (tribal or specialized snake-catchers) in collecting and selling snakes to venom laboratories. The snakes, which have an average lifespan of 10-20 years in the wild, are kept for venom extraction until they die, generally in the course of a few months.

There have been few, if any, studies on the impact of collection of large numbers of snakes for commercial use. However, personal observation, anecdotal references and information about the rattlesnake round-ups in the USA, indicate that snake populations can be quite vulnerable and adversely affected by over-collection. This was the rationale that led to the system of capture/extraction/release used by the Irula co-operative. The system was also acceptable to the government licensing authority (the Tamil Nadu State Forest Department), which needed to be convinced that exploitation of these snakes would have a minimal impact on their populations. All snakes are protected under the Wildlife Protection Act. The cobra and Russell's viper are on Schedule II, which prohibits capture and trade; an exception has been made for the purpose of venom collection. The saw-scaled

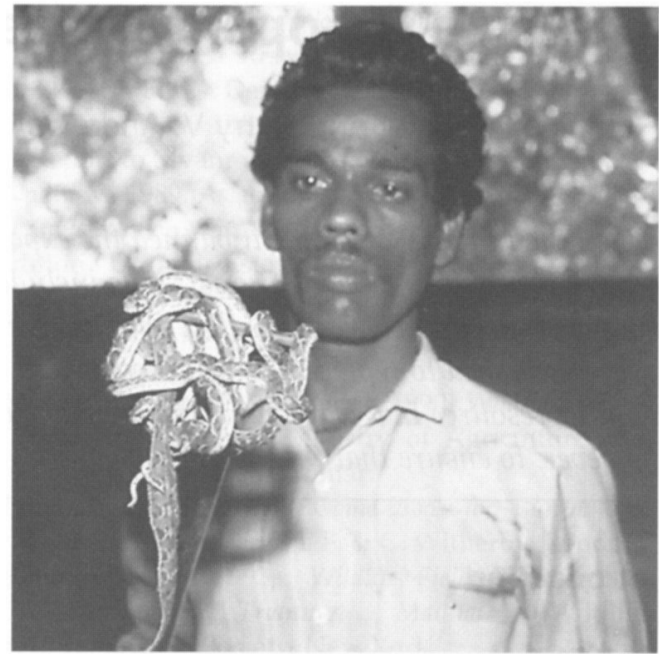

Above: An Irula snake collector with saw-scaled vipers ( $R$. Whitaker).

Left: In the early 1970 s millions of snake skins were exported annually ( $R$. Whitaker).

viper and krait are protected under Schedule IV, which allows capture and trade only under licence. These laws have discouraged people from initiating other venom projects in India, although two state government projects exist. One, the Haffkine Institute in Bombay, buys snakes from anyone, and the other, the King Institute in Madras, buys primarily from Irulas.

One per cent of snakes die at the venom centre while captive. Provided there is a similar low mortality rate once the snakes are released back to the wild, this usage constitutes no threat to the future use potential or longterm viability of snake populations. The snakes are caught from very disturbed habitats - farmland, degraded scrub forests and hedgerows. Throughout the year these habitats have a superabundance of prey animals, such as rodents and amphibians, which are both benefited by rice farming. Snake densities in these areas are probably much higher than in pristine forest habitats; there is little published data to support this hypothesis but years of personal observation and the experience of Irula hunters bear it out. In general, the conversion of forest to farmland and fal- 
low land is apparently beneficial to three of the four species of snakes exploited by the Irulas. Only Russell's viper is predominantly a forest species. Unless bounded by dense hedgerows (preferably of cactus and agave), farmlands are not good habitats for this species, even though the prey resource is enhanced. This is the one species of the four that seems fairly vulnerable to degradation of its natural habitat. The saw-scaled viper, on the other hand, which is a small species that prefers dry rocky areas and small thorn bushes, seems to benefit from the conversion of scrub forest to open wasteland. The cobra and krait are both hole-dwellers and also appear to flourish in relatively disturbed habitats, mainly farmland.

\section{The Irula approach to the use of snakes for venom extraction}

The Irula Co-operative Venom Centre was set up for one main reason: to provide the Irulas with income-generating employment, which used their traditional skills without over-exploiting any taxa of wildlife. Snake venom was an obvious choice because Irulas were skilled traditional snake-catchers and possessed a good knowledge of snake natural history. At first, little attention was paid to the status of the snake populations, harvest levels and other considerations. The number of snakes caught was set by the Tamil Nadu State Forest Department and each of the 101 members of the co-operative was given an annual quota of snakes.

Irulas, in the manner of hunter-gatherers everywhere, hunt the area around their village or encampment as far as they can easily walk with their families in one day. They seldom travel further and this limits the impact of their exploitation of local wildlife resources. The Irulas find the snakes mainly by searching for tracks, faeces and shed skins at rat holes, termite mounds and dense hedgerows. Snakes are dug out with short crow bars, pinned and bagged. The snakes that are caught - usually one to three large snakes are captured on a good day - are sold to the venom centre.
Before 1976, when the skin industry was banned, the Irulas caught and killed millions of snakes (primarily cobras and Russell's vipers) each year in the same area where they now catch around 6000 annually for their venom from an area of $500 \mathrm{sq} \mathrm{km}$. It appears that this greatly reduced use is sustainable, especially because most of the snakes are released, but it is important that an adequate evaluation of the whole system be made to provide empirical evidence to support this. The project is fortunate in having the co-operation of the Tamil Nadu State Forest Department with whom we worked out a legal framework for licensing and accounting for the snakes caught, the amount of venom collected, and the supervised release of the snakes back to the wild.

The Irulas benefit directly from the snake captures and subsequent sale to their co-operative, but other local people have little love for snakes and will kill them on sight, even though the cobra is revered by Hindus. Part of the work of the venom centre is to publicize the use of antivenom serum, and stress the fact that most snakes are harmless and that it is fairly easy to identify the four medically important species. It is further stressed to visitors to the venom centre and to the farmers with whom the Irulas interact daily, that snakes are extremely valuable because of the destructive rodents they consume.

Irulas have no formal methods of assessing the sustainability of their uses of wild species, but their sensitivity to changes in habitat, changes in season and knowledge of the biology of these species allow them to be effective exploiters. They will not hunt depleted areas because it is simply not energy-efficient. Irulas will not over-collect in an area because they are generally satisfied with an income that satisfies their immediate needs. Irulas hunt snakes intensively for a few days, enough to make the money they need for their families for a few weeks, and then tend to switch to hunting food animals - rats, hares, mongooses, monitor lizards and turtles - and gathering food and medicinal plants. They have a religious regard for many things in nature, including the cobra (their main goddess is Naga- 


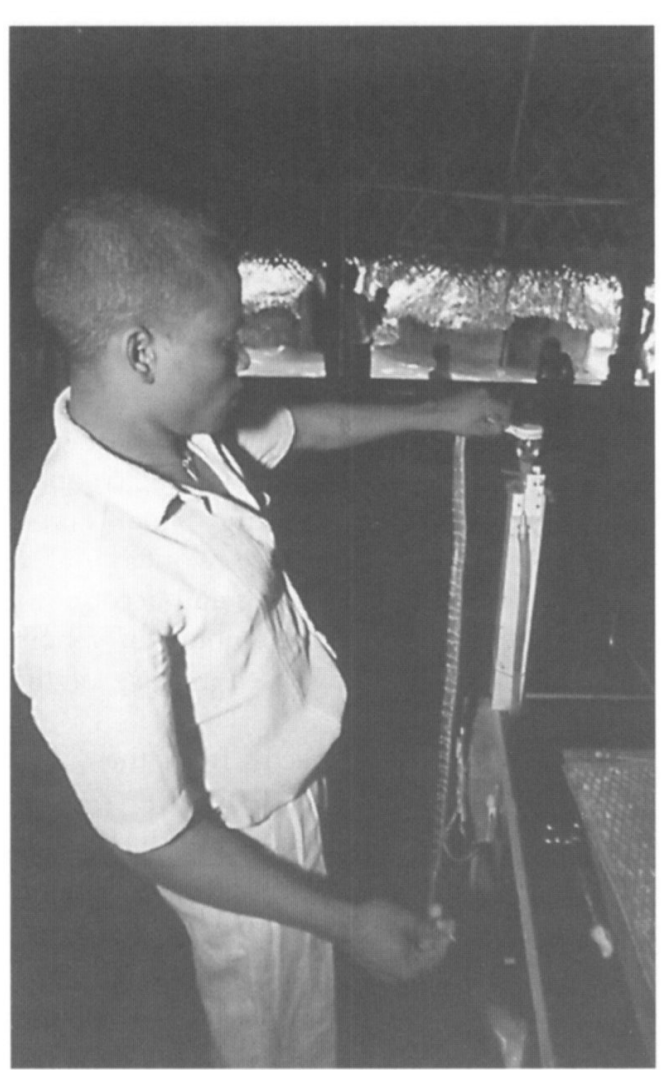

An Irula extracting krait venom ( $R$. Whitaker).

kanni, literally 'cobra virgin') and the edible tuber veli kodi kezhang (Pouzolzia zeylancia). Men and women generally collect this tuber from the scrub forest by locating the vine, digging up the tuber and then replanting the top left connected to the vine. This practice is a form of forest agriculture in which the plant is carefully used and allowed to regrow to produce another tuber (Prescott-Allen, 1990).

\section{Species maintenance}

Every effort is made at the venom centre to ensure that capture and venom extraction are both sustainable and humane. The duration of captivity is limited to 3 weeks and milking is performed only once each week. The snakes are kept in mud pots, which allow quick and easy handling and keep the snakes cool. At the start of the project, the mortality rate of snakes was 1.3 per cent of captures, mainly during the summer months when temperatures are $38-41^{\circ} \mathrm{C}$. Sprinkling water and keeping the snake pit cool has reduced mortality to below 1 per cent.

Care is taken to ensure that the extractor is gentle when pinning the snakes, and the entire process of venom extraction does not take longer than 2 minutes per snake. The animals are given water but not food; healthy snakes can do well without food for many weeks. All snakes are released to nearby Reserved Forests.

To detect and prevent premature recapture and to provide biological data, the length, weight, date and place of capture are recorded for all individuals. In addition, all snakes, except for saw-scaled vipers, which at a maximum of $30 \mathrm{~cm}$ long are too small, are coded by clipping the ventral scales. Clip-codes last from 6 months to 2 years. The rate of recapture within this period is extremely low: of over 13,000 of the large species that have been caught, only 20 have had codes.

To avoid pressures on too few populations, snakes are caught throughout the district by members from widely scattered villages. The venom centre does not accept juvenile snakes, and members are discouraged from collecting gravid females.

\section{Evaluation procedure}

It is hoped that the venom centre will expand its activities to other parts of the state, increasing quantities of venom production. It may also start venom collection from other species of snakes as well as export of venom. While it does not appear that the Irula snake venom project is having much impact on populations of the target species, evaluating the snake resource and other factors is considered important for the project's long-term sustainability. The following studies are required:

- an investigation into population status and dynamics of the four medically important snakes in Chinglepet District, the area of licensed snake-hunting operations by the Irulas; 
- a study of the importance of snakes as predators on crop-destroying rodents;

- research into changes in snake habitat and prey abundance, and into the effect of agricultural pesticides and other factors on snake populations in the long term;

- determination of the numbers of snakes needed to provide sufficient venom for India's antivenom serum requirements;

- an investigation of snake mortality in captivity;

- an assessment of survival rates of snakes released after venom extraction;

- analysis of potential economic benefits to the Irula community.

There are few studies on snake population dynamics in other parts of the world (see; for example, Brown, 1991), but none has been carried out in India. For the four species we are concerned with here, a 3-year study is required involving at least two full-time researchers at postgraduate level with laboratory and logistical support from an institution such as the Centre for Herpetology in Madras. It is estimated that such a study would cost $\$ 30,000-40,000$. The necessary field research would be cost-effective because of the low overheads combined with the availability of highly qualified personnel and the very important technical input of the Irulas themselves.

Many species of snakes, including the cobra, krait and Russell's viper, consume large numbers of rodents. Some data exist indicating the importance of these predators in controlling crop pests, such as the lesser mole rat Bandicota bengalensis and rice rat Rattus meltada (Whitaker and Advani, 1983; Whitaker, 1984). Removing snakes from croplands for venom extraction could favour rodents (and therefore crop damage) and should be evaluated by carrying out a comprehensive field-study. Past and current studies on the habitats, prey and other factors of importance to snake populations can be researched and applied with specific regard to snake status and viability.

Snake mortality in captivity at the Irula coperative is recorded routinely because the Forest Department requires an exact, up-todate inventory of all snakes caught and main- tained for venom extraction. Various modifications and improvements in maintaining the snakes during captivity have been made over the years to minimize mortality. A 3-week period in captivity, during which three to four venom extractions are made, was decided upon because the snakes start to lose weight after that length of time without food. It is important that the snakes are healthy and strong at the time of release.

Assessing the survival rates of snakes after release will be difficult and time-consuming. The snakes are generally captured in and around farms adjacent to villages. However, they cannot be released in the same places because the local people do not want them back. Instead, the snakes are released in Reserved Forests, which consist of degraded scrub forest and plantations of cashew nuts and eucalyptus. It is probable that snakes migrate back to their preferred cropland habitats, but it is possible that there is some mortality before they reach the habitat that provides them with optimum prey and shelter. In addition, it is possible that snakes moved to unfamiliar territories may have difficulty adapting to their new environment.

The Tamil Nadu State Forest Department, on whose co-operation the project depends for licences and snake quotas, is particularly interested in the fate of snakes after release and, to this end, a brief pilot study was carried out in 1991. About 100 kraits were released with fluorescent paint marks on their backs. Searches were made by day and night for a week following the release. Very few snakes were seen and these only at night, suggesting that all (except one found dead) had found shelter in the scrub forest or migrated to rat holes in nearby croplands. It is proposed to carry out an intensive study of this kind based on capture/mark/recapture techniques. Such a study could produce results in a 12-month period with one researcher plus Irula assistants and would cost $\$ 10,000-15,000$.

The Venom Centre needs to accept the responsibility for carrying out the studies and monitoring detailed above and at the time of writing (November 1994) is seeking donors and collaboration to undertake them. 


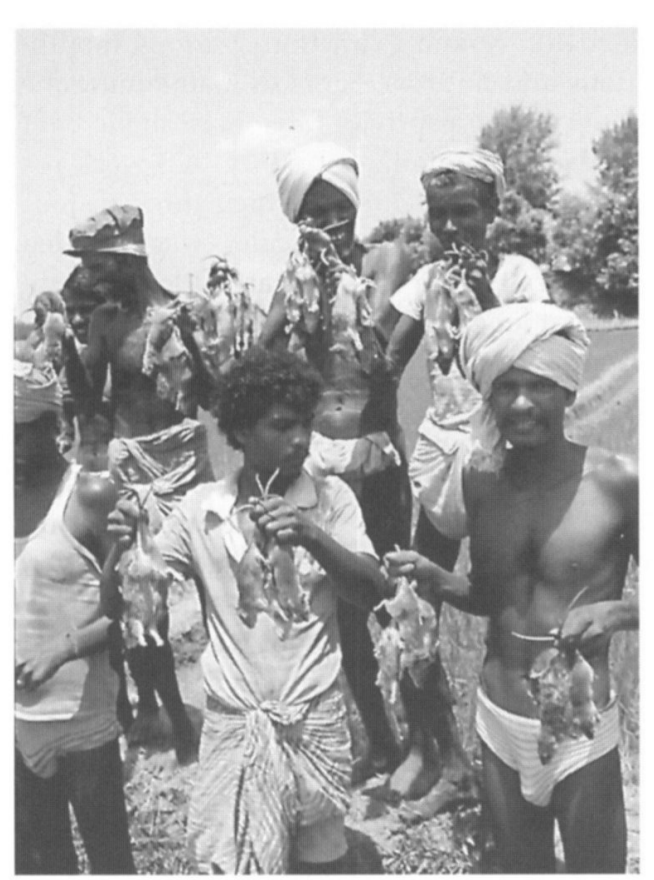

Irulas with a mornng's catch of field rats (R. Whitaker).

\section{Project sustainability}

Compared with other sustainable use of wildlife projects, the Irula project is unusual. The resource base appears to be large and, in most cases, the habitat of the species concerned is actually increasing. Close to 100 per cent of the snakes are released after the commercial product is extracted and it appears that survival of the released snakes is high.

One of the important achievements of the Venom Centre is the application of tribal technology to generate income and use wild snakes sustainably. There is no change in tribal tradition in this application of commercial wildlife use and the only imported technology is the rather simple one of venom extraction and processing. The Co-operative is now the largest producer of venom in India. Except for 3 years, when there were delays in licensing and little venom was purchased, the project has made a profit since its inception. Since 1984 it has been financially self-sufficient for basic costs through its venom sales (95 per cent of income) and sale of tickets to visitors wishing to observe the venom extraction process (5 per cent of income). Basic costs include salaries and administrative costs but not transport (the project needs one more jeep) or research (on snake biology and ecology).

\section{Related projects}

The Irulas are also skilful rat catchers and rats are the largest source of protein in their diet. Because of their skill, they are hired by farmers desperate to reduce the tremendous annual losses of rice to the rodents. A pilot project to demonstrate the cost-effectiveness of the Irula approach to rat control compared with standard pesticide use was carried out in 1984 with the support of Oxfam (India). Subsequently the Indian Government granted Rs250,000 for a larger project over a 2-year period. The results were so encouraging $(200,000$ rats caught, tons of grain saved) that the establishment of an Irula-operated pest-control agency is being considered (Whitaker amd Murali, 1988).

The Irula Tribal Women's Society was set up in 1986 with the focus being the establishment of nurseries of forest trees and reforestation of fallow public and private lands. The Society received a grant of Rs1 million from the National Wasteland Development Board and has been actively planting since that time. Now, with over 175 members, the growing and marketing of medicinal plants is a primary focus and the project includes an education centre for the tribal people with funds from NORAD, Canada Fund, Indo-German Social Service Society, Womankind and Oxfam.

The next project being considered is commercial crocodile farming. The Madras Crocodile Bank, a private trust operated by the authors and a Board of Trustees, produces a surplus of over 5000 crocodile eggs each year. Current legislation prevents the commercial use of crocodiles in India, but we have drafted a project to submit for government approval that would allow the Irulas to use this surplus. Crocodile eggs or young would be purchased from the Crocodile Bank and 
reared for meat (for local use) and skins (for export and foreign exchange earnings). The projections of profitability of such an operation are excellent and, considering that hundreds of thousands of rats would need to be caught to feed the crocodiles, the rice farmers would stand to benefit as well.

The Irula Co-operative has the potential to expand, given some additional financial input plus encouragement from the government. If larger quotas were granted, snake venom could be exported for medicinal and research uses. Other species of snakes (for example, sea snakes and pit vipers) with very valuable venoms could be added to the list of those now being used. Research needs to be done both related directly to the venom centre's operations and on snakes and rodents in general. More facilities and help for the Irulas (considered to be one of the poorest tribes in India) are also needed. As a good example of how one tribe of skilled naturalists can earn a living using traditional knowledge and using wildlife sustainably, the Irula Co-operative Venom Centre deserves local and international inputs of assistance, funds and technology.

\section{Acknowledgements}

We wish to thank E. D. S. Shymala and S. Dravidamani of the Irula Co-operative Venom Centre for providing the co-operative's statistics and Harvey Lillywhite for reading and commenting on the manuscript.

\section{References}

Brown, W.S. 1991. Female reproductive ecology in a northern population of the timber rattlesnake (Crotalus horridus). Herpetologia, 47 (1).

Prescott-Allen, C. and Prescott-Allen, R. 1990. Snake Venom Production, India. Unpubl. report to IUCN/SSC Sustainable Use of Wildlife Specialist Group.

Sawai, Y. and Homma, M. 1976. Snakebites in India. In Animal, Plant and Microbial Toxins, Vol. 2. pp. 451-460. Plenum Publishing Corp, New York.

Swaroop, S. and Grab, B. 1954. Snake bite cases in India. Bulletin of the WHO, 10 (1), 35-76.

Whitaker, R. 1984. The Role of Reptiles in Controlling Food Pests. Impact of Non-insect Pests and Predators on Food Production. All India Scientific Writers Society, New Delhi.

Whitaker, R. and Advani, R. 1983. Preliminary field study on snakes as agents of management of rodent populations. Indian Forester, 109 (6), 417-419.

Whitaker, R. and Murali, M. 1988. Rodent control by Irula tribals. Journal of the Bombay Natural History Society, 85, 263-270.

Whitaker, Z. 1979. Artful catchers, deadly prey International Wildlife, March/April, 27-33.

Whitaker, Z. and Whitaker, R. 1987. Irula tribal cooperative. Cultural Survival Quarterly, 11(1), 31-33.

Romulus Whitaker, Director, Centre for Herpetology, Madras Crocodile Bank, Post Bag 4, Mamallapuram 603 104, Tamil Nadu, India.

Harry V. Andrews, Deputy Director, Centre for Herpetology, Madras Crocodile Bank, Post Bag 4, Mamallapuram 603 104, Tamil Nadu, India. 